\title{
Successful treatment of stress-induced cognitive impairment with haloperidol; evaluation also warranted in hematopoietic stem cell transplantation
}

\author{
Marlies E.H.M. Van Hoef
}

Correspondence: mvanhoef@transplantcreations.com

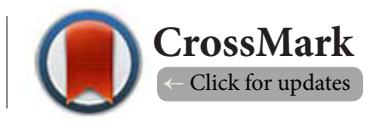

Belp, Switzerland.

\begin{abstract}
Cognitive impairment in patients with hematologic malignancies has been reported since over two decades and has been observed in the course of treatment prior to and after hematopoietic stem cell transplantation. Most reports attribute the dysfunction to the effect of treatment on the nervous system and focus on diagnosis and a battery of cognitive function tests. Whether cognitive impairment results from the effect of the treatment or is stress related has not been examined. Effective therapy is not known. Spontaneous improvement by time has been reported. Herein literature is reviewed, a case of stress induced cognitive impairment presented, successful treatment for the dysfunction described and the physiological mechanism explained.
\end{abstract}

Keywords: Cognitive impairment, stress, cancer, leukemia, lymphoma, multiple myeloma, hematopoietic stem cell transplantation, haloperidol

\section{Introduction}

Cognitive impairment has been reported in the course of treatment for hematologic malignancies and has been observed prior to and after hematopoietic stem cell transplantation (HSCT); whether the impairment is caused by damage induced by therapy to neurological structures or by the stress and potential post-traumatic stress syndrome that may occur is not known. Cognitive impairment is defined as dysfunction in one or more cognitive domains, including intelligence, language, memory, attention and executive function such as divergent thinking and reasoning, visuospatial organization, psychomotor speed and speed of information processing. Most publications address diagnosis and a battery of test to evaluate functioning in cognitive domains at various points in time but most donot address treatment for the cognitive dysfunction. Herein the literature is briefly reviewed, a patient is decribed who developed stress induced cognitive dysfunction and observed decrease in capacity and was successfully treated with haloperidol, and the physiological mechanism is explained.

Cognitive impairment associated with hematopoietic cell transplantation

Andrykowski et al., reported cognitive dysfunction in adult acute and chronic leukemia survivors after HSCT [1]. The study evaluating cognitive function at a mean of 47 months after transplant used self reported questionnnaires and revealed that increased doses of total body irradiation (TBI) were associated with increased cognitive dysfunction. The relationship remained after the impact of psychological distress was accounted for. TBI related cognitive impairment primarily involved slow reaction time, reduced attention and concentration difficulties in reasoning and problem solving.

Two years later the same author reported neuropsychologic impairment in adult bone marrow candidates [2]. The paper suggests that neuropsychologic performance was associated with specific disease and treatment risk factors in particular a history of irradiation or central nervous system disease treated with intrathecal chemotherapy. Performance on tests reflecting memory of higher cognitive processing was more likely to be impaired. The risk of impairment increased with the number of disease and treatment risk factors for cognitive impairment. Phipps et al., examined the psychological effects of bone marrow transplantation in 64 children and adolescents, and reported 25 pediatric bone marrow transplant survivors who were evaluated before and 6 to 12 months after transplantation [3]. Cognitive and neuropsychological function remained 
stable during the study period. They concluded that no association between bone marrow conditioning regimens and significant neuropsychologic impairment was observed in the first year after transplant, but that this period is characterized by significant psychosocial difficulties for survivors.

Harder et al., reported 40 patients with hematological malignancies who were examined with a battery of neuropsychological tests and were minimal two years progression free after allogeneic transplantation [4]. All had received 12 cG TBI. Assessment took place up to 82 months after bone marrow transplantation. Mild to moderate impairment was found in 24 patients; selective attention and executive function, information processing speed, verbal learning and verbal and visual memory were most likely affected. The EORTC QLQ-C30 cognitive function was strongly correlated with symptom fatigue. Cognitive deficits were less outspoken after autologous transplantation compared to matched unrelated transplantation.

Booth-Jones et al., examined 65 patients with breast cancer, leukemia, lymphoma and multiple myeloma 6 months after transplantation in seven cognitive domains, including attention, verbal learning, verbal memory, visual memory, simple executive function, complex executive function and psychomotor speed [5]. 51\% had mild cognitive impairment and $28 \%$ moderate or severe impairment. Breast cancer transplant recipients six months post transplant showed cognitive deficits mainly in psychomotor speed and executive function. Older patients and patients with lower IQ more likely scored in the impaired range. Young patients reported significantly more complaints. Complaints did not always correlate with objective findings. Poor cognitive function was associated with poor quality of life.

Harder et al., reported 25 hematological patients who were examined before and the first year after HSCT [6]. In comparison to normal data, up to $25 \%$ experienced impaired functioning on several cognitive domains before stem cell transplantation. Impairment in neurocognitive functions was positively related to depression and anger at baseline and the emotional functioning scale at follow-up.

Schultz-Kindermann et al., examined cognitive functioning before $(n=39)$ and 3 months after $(n=19)$ allogeneic transplantation for hematological malignancies [7]. They found that 26\% of patients was impaired before as well as after transplant, but simple reaction time was significantly worse. They identified age, more cycles induction therapy, cumulative treatments as seen in advanced disease, post induction deficits and pretransplant emotion status as predisposing factors.

Poppelreuter et al., screened 157 patients with hematological malignancies and evaluated 96 for cognitive deficits following hematopoietic cell transplantation in the in-patient setting [8].

They were assigned to either neuropsychological training, PC training or a control group. Testing was done at posttransplant start and end of rehabilitation and six months later.
The results showed that neuropsychological training did not result in more improvement than PC or no training. No difference was found between age groups, gender, autologous and allogeneic transplant recipients. They found that cognitive deficits may improve but donot restore compared to the norm six months after HSCT.

Friedman et al., reported 117 patients before HSCT of whom 33 received evaluations six and twenty eight weeks post HSCT [9]. Of 117 patients 39\% were classified as impaired before HSCT; the authors show a decline in $47 \%$ of 33 patients at six weeks and in $33 \%$ of these further decline occurred twenty six weeks after transplantation. Verbal learning, psychomotor speed and executive function showed greatest vulnerability compared to prehematopoietic stem cell transplantation.

Surjala et al., reported that cognitive disorders occur before and after high dose allogeneic transplantation, with partial recovery by one year [10]. Follow-up five years after transplantation showed that survivors $(n=92)$ at the time diagnosed with various hematological malignancies recovered significant cognitive function from post transplantation to five years in all tests. Verbal fluency and executive function improved but motor dexterity did not. In global deficit score $41.5 \%$ of survivors and $19.7 \%$ of controls ( $n=66$ ) had mild or greater deficits at five years compared to matched controls.

Also Sherwart et al., reported cognitive dysfunction pre- and post HSCT in 102 patients [11]. Before and after transplantation 50\% performed below tests norms. Impairment of one or more domains was found in $47 \%$ before and $41 \%$ after transplantation.

Jones et al., reported the prevalence of cognitive dysfunction in 53 patients with multiple myeloma after induction and one and three months after autologous transplantation [12]. Deficits were observed in learning, memory, executive function, motor function and psychomotor speed. Before transplantation $47 \%$ of patients had cognitive impairments as measured by the overall cognitive function index. At one and three months post-transplant a decline was observed in $49 \%$ and $48 \%$ of patients.

\section{Case history}

A healthy subject noticed a decline in function during a longterm stressful situation; it was not until extreme stress was imposed that the subject experienced cognitive impairment; she had difficulty writing letters, handling large documents and composing a presentation. She later reported her capacity to be $10 \%$ compared to that before the stressful situation. The subject was not treated but the cognitive impairment and decreased performance slowly improved. It was not until a couple of years later that she developed burn out and was treated with haloperidol; at that time she noticed that her writing skills, that had already substantially improved, showed rapid further improvement after about 3 weeks of therapy. She was treated for nine months with haloperidol $2 \mathrm{mg} /$ day, during which she resumed work at her level of 
expertise. Recurrance of decrease in performance occurred a few years later when renewed exposed to a several months lasting stressful situation. The decrease in performance could not be overcome with rest. Reinstatement of haloperidol 2 $\mathrm{mg} /$ day resolved her condition in three weeks time. After four months on alternative 1 and $2 \mathrm{mg}$ each other day therapy was stopped and since that time the impairment has not recurred. The dose of $2 \mathrm{mg} /$ day was well tolerated.

\section{Results and discussion}

Cognitive impairment is reported prior to and after HSCT. The pattern observed is not consistent, but in general impairment increases with the number of treatments pretransplant and is more outspoken post-transplant. In survivors by time improvement spontaneously occurs but generally not to the norm observed in healthy subjects. Also in other cancers than hematological malignancies cognitive impairment after treatment has been reported $[5,13,14]$.

Although the cognitive dysfunctioning is often described as chemobrain, the dose of chemotherapy is not a predictive factor, and cognitive impairment has been observed after autologous and ablative and reduced intensity conditioning allogeneic transplants. Although chemotherapy induced damage of the white and grey matter of the brain has been reported to be causative, several publications connote that emotion and anxiety associated with the disease and it's treatment play a role $[6,7,15]$.

Stress effects are associated with prefrontal cortical cognitive deficits [16]. In an animal study was shown that noice stress increased dopamine turn over in the prefrontal cortex, impaired delayed response performance and induced prefrontal cortical acute cognitive impairment [17]. Delayed response performance was improved by treatment with the dopamine receptor inhibitor haloperidol. Pretreatment with haloperidol reduced dopamine turn over and ameliorated stress-induced deficits in delayed response performance.

In humans the effect of haloperidol on cognitive impairment has not been studied in relation to cancer therapy, but has been reported in a psychiatric disorder [18-20].

The observation in animals and the experience of the healthy subject in the case suggests a curative effect of haloperidol on stress induced cognitive impairment. The effect by the subject was twice first observed after three weeks of therapy; the duration of need for treatment in stress induced cognitive dysfunction is not known. Durable treatment had been recommended but this was not necessary.

Exploration of haloperidol in patients who experience cognitive impairment in the course of treatment for hematological malignancies is warranted.

\section{Competing interests}

The author declares that she has no competing interests.

\section{Publication history}

EIC: Evangelos Terpos, University of Athens School of Medicine, Greece.

Received: 19-Nov-2014 Final Revised: 22-Dec-2014

Accepted: 06-Jan-2015 Published: 13-Jan-2015

\section{References}

1. Andrykowski MA, Altmaier EM, Barnett RL, Burish TG, Gingrich R and Henslee-Downey PJ. Cognitive dysfunction in adult survivors of allogeneic marrow transplantation: relationship to dose of total body irradiation. Bone Marrow Transplant. 1990; 6:269-76. | Article | PubMed

2. Andrykowski MA, Schmitt FA, Gregg ME, Brady MJ, Lamb DG and Henslee-Downey PJ. Neuropsychologic impairment in adult bone marrow transplant candidates. Cancer. 1992; 70:2288-97. | Article | PubMed

3. Phipps S, Brenner M, Heslop H, Krance R, Jayawardene D and Mulhern R. Psychological effects of bone marrow transplantation on children and adolescents: preliminary report of a longitudinal study. Bone Marrow Transplant. 1995; 15:829-35. | Article | PubMed

4. Harder H, Cornelissen JJ, Van Gool AR, Duivenvoorden HJ, Eijkenboom WM and van den Bent MJ. Cognitive functioning and quality of life in long-term adult survivors of bone marrow transplantation. Cancer. 2002; 95:183-92. | Article | PubMed

5. Booth-Jones M, Jacobsen PB, Ransom S and Soety E. Characteristics and correlates of cognitive functioning following bone marrow transplantation. Bone Marrow Transplant. 2005; 36:695-702. | Article | PubMed

6. Harder H, Duivenvoorden HJ, van Gool AR, Cornelissen JJ and van den Bent MJ. Neurocognitive functions and quality of life in haematological patients receiving haematopoietic stem cell grafts: a one-year follow-up pilot study. J Clin Exp Neuropsychol. 2006; 28:283-93. | Article | PubMed

7. Schulz-Kindermann F, Mehnert A, Scherwath A, Schirmer L, Schleimer $B$, Zander AR and Koch U. Cognitive function in the acute course of allogeneic hematopoietic stem cell transplantation for hematological malignancies. Bone Marrow Transplant. 2007; 39:789-99. | Article | PubMed

8. Poppelreuter M, Weis J, Mumm A, Orth HB and Bartsch HH. Rehabilitation of therapy-related cognitive deficits in patients after hematopoietic stem cell transplantation. Bone Marrow Transplant. 2008; 41:79-90. | Article | PubMed

9. Friedman MA, Fernandez M, Wefel JS, Myszka KA, Champlin RE and Meyers CA. Course of cognitive decline in hematopoietic stem cell transplantation: a within-subjects design. Arch Clin Neuropsychol. 2009; 24:689-98. | Article | PubMed

10. Syrjala KL, Artherholt SB, Kurland BF, Langer SL, Roth-Roemer S, Elrod $J B$ and Dikmen S. Prospective neurocognitive function over 5 years after allogeneic hematopoietic cell transplantation for cancer survivors compared with matched controls at 5 years. J Clin Oncol. 2011; 29:2397404. | Article | PubMed Abstract | PubMed Full Text

11. Scherwath A, Schirmer L, Kruse M, Ernst G, Eder M, Dinkel A, Kunze S, Balck F, Bornhauser M, Ehninger G, Dolan K, Gramatzki M, Kolb $H J$, Heussner P, Wilhelm H, Beelen DW, Schulz-Kindermann F, Zander $A R$, Koch $U$ and Mehnert $A$. Cognitive functioning in allogeneic hematopoietic stem cell transplantation recipients and its medical correlates: a prospective multicenter study. Psychooncology. 2013; 22:1509-16. | Article | PubMed

12. Jones D, Vichaya EG, Wang XS, Sailors MH, Cleeland CS and Wefel JS. Acute cognitive impairment in patients with multiple myeloma undergoing autologous hematopoietic stem cell transplant. Cancer 2013; 119:4188-95. | Article | PubMed Abstract | PubMed Full Text

13. Bender CM and Merriman JD. Cancer- and treatment-related cognitive changes: what can we do now? What lies ahead? Oncology (Williston Park). 2014; 28:pii 201379. | Article | PubMed Abstract | PubMed Full Text

14. Patel SK, Hurria A and Mandelblatt JS. Chemobrain: is it time to initiate 
Marlies E.H.M. Van Hoef, Hematology and Leukemia 2015,

http://www.hoajonline.com/journals/pdf/2052-434X-3-1.pdf

guidelines for assessment and management? Oncology (Williston Park). 2014; 28. | Article | PubMed

15. Schagen SB and Weferl JS. Chemotherapy-related changes in cognitive functioning. EJC Supple. 2013; 11:225-232. | Article

16. Deutch $A Y$ and Roth RH. The determinants of stress-induced activation of the prefrontal cortical dopamine system. Prog Brain Res. 1990; 85:367-402. | PubMed

17. Arnsten AF and Goldman-Rakic PS. Noise stress impairs prefrontal cortical cognitive function in monkeys: evidence for a hyperdopaminergic mechanism. Arch Gen Psychiatry. 1998; 55:362-8. | Article I PubMed

18. Harvey PD, Rabinowitz J, Eerdekens M and Davidson M. Treatment of cognitive impairment in early psychosis: a comparison of risperidone and haloperidol in a large long-term trial. Am J Psychiatry. 2005; 162:1888-95. | Article | PubMed

19. Gallhofer B, Jaanson P, Mittoux A, Tanghoj P, Lis S and Krieger S. Course of recovery of cognitive impairment in patients with schizophrenia: a randomised double-blind study comparing sertindole and haloperidol. Pharmacopsychiatry. 2007; 40:275-86. | Article | PubMed

20. Davidson M, Galderisi S, Weiser M, Werbeloff N, Fleischhacker WW, Keefe RS, Boter H, Keet IP, Prelipceanu D and Rybakowski JK et al. Cognitive effects of antipsychotic drugs in first-episode schizophrenia and schizophreniform disorder: a randomized, open-label clinical trial (EUFEST). Am J Psychiatry. 2009; 166:675-82. | Article | PubMed

\section{Citation:}

Van Hoef MEHM. Successful treatment of stress-induced cognitive impairment with haloperidol; evaluation also warranted in hematopoietic stem cell transplantation.

Hematol Leuk. 2015; 3:1.

http://dx.doi.org/10.7243/2052-434X-3-1 